Article

\title{
Apocope in Heritage Italian
}

\author{
Anissa Baird ${ }^{1}$, Angela Cristiano ${ }^{2}$ and Naomi Nagy ${ }^{1, *}$ \\ 1 Department of Linguistics, University of Toronto, Toronto, ON M5S 3G3, Canada; \\ anissa.baird@mail.utoronto.ca \\ 2 Department of Classical Philology and Italian Studies, Università di Bologna, 40126 Bologna, Italy; \\ angela.cristiano989@gmail.com \\ * Correspondence: naomi.nagy@utoronto.ca
}

check for updates

Citation: Baird, Anissa, Angela Cristiano, and Naomi Nagy. 2021. Apocope in Heritage Italian. Languages 6: 120. https://doi.org/ 10.3390/languages6030120

Academic Editors: Robert Mayr and Jonathan Morris

Received: 25 February 2021

Accepted: 7 July 2021

Published: 13 July 2021

Publisher's Note: MDPI stays neutral with regard to jurisdictional claims in published maps and institutional affiliations.

Copyright: (c) 2021 by the authors. Licensee MDPI, Basel, Switzerland. This article is an open access article distributed under the terms and conditions of the Creative Commons Attribution (CC BY) license (https:// creativecommons.org/licenses/by/ $4.0 /)$.

\begin{abstract}
Apocope (deletion of word-final vowels) and word-final vowel reduction are hallmarks of southern Italian varieties. To investigate whether heritage speakers reproduce the complex variable patterns of these processes, we analyze spontaneous speech of three generations of heritage Calabrian Italian speakers and a homeland comparator sample. All occurrences $(\mathrm{N}=2477)$ from a list of frequent polysyllabic words are extracted from 25 speakers' interviews and analyzed via mixed effects models. Tested predictors include: vowel identity, phonological context, clausal position, lexical frequency, word length, gender, generation, ethnic orientation and age. Homeland and heritage speakers exhibit similar distributions of full, reduced and deleted forms, but there are inter-generational differences in the constraints governing the variation. Primarily linguistic factors condition the variation. Homeland variation in reduction shows sensitivity to part of speech, while heritage speakers show sensitivity to segmental context and part of speech. Slightly different factors influence apocope, with suprasegmental factors and part of speech significant for homeland speakers, but only part of speech for heritage speakers. Surprisingly, for such a socially marked feature, few social factors are relevant. Factors influencing reduction and apocope are similar, suggesting the processes are related.
\end{abstract}

Keywords: heritage language; apocope; vowel centralization; vowel reduction; variationist sociolinguistics; Calabrese; Italian

\section{Introduction}

Heritage language (HL) sociolinguistics generally targets "conflict sites" (Poplack and Meechan 1998), that is, portions of a language that differ from the majority language (English, in many HL studies), in order to determine the degree of influence of English on the given heritage language. Frequent examples are pro-drop (cf. Otheguy et al. 2007; Silva-Corvalán 1994) and voice onset time (Nagy and Kochetov 2013). Sometimes the investigations are framed in terms of "simplification" or "attrition" of the HL grammar, but that often coincides with becoming more English-like.

Instead, this paper examines an indigenous pattern of variation, one that appears in non-heritage varieties and, thus, is not attributable directly to contact effects of the majority language in the heritage context. In this first empirical sociolinguistic investigation of the two related phenomena of word-final vowel reduction and apocope (word-final vowel deletion) in Italian, our primary goal is to establish the distribution of contexts in which full, reduced and deleted word-final vowels occur. That is, we first establish the relative frequency of each variant in each context in which it occurs, and what factors, linguistic and social, condition the variability. This contributes to understanding how and if the two processes are related to each other-i.e., if apocope is the final stage of a reduction process (cf. Sections 2.1 and 6). We first describe the diatopic variation in Italy and Calabria, describing the conversational speech we recorded as 'Regional Italian'. Section 2.1 discusses two possible changes to vowels-reduction and deletion, focusing on word-final vowels in Calabria. 
Our second goal is to determine the extent to which Heritage Italian speakers, living in Toronto, replicate the grammar that conditions this variability, including sensitivity to both linguistic and social factors. In addition to social factors such as age and gender that are predicted to influence homeland speakers, we consider generation (since immigration) and an array of ethnic orientation measures for the heritage speakers. It is important to note that, for heritage-language speakers, use of the language is, generally, more restricted to casual (at home) contexts than is the case for speakers in Italy. Hjelde et al. (2019, p. 186) note that heritage language speakers often are "able to use the heritage language but with a reduced register and with lexical and grammatical reductions, and with deviations compared to the baseline," likely resulting from the restricted contexts of use, see Section 2.2.

\section{Language Varieties in Italy}

The Italian linguistic repertoire is complex and multidimensional. Therefore, systematic descriptions, based on spontaneously produced speech (talk-in-interaction), of the main aspects of this system are important for understanding the factors that influence Italian speech.

The diatopic axis plays a primary role in the Italian picture: Berruto (2006) sets geographic variation as the basis for all the other types of variation, with which it intertwines. Some scholars claim that certain patterns only emerge in spontaneous speech (cf. Abete 2011; Sornicola 2002). Local and Walker (2005) set the use of ecologically valid data, drawn from talk-in-interaction, such as the interviews we examine, as imperative for the study of the phonetic organization of spontaneous speech.

An important consequence is that every geographic variety has its own diaphasic (stylistic) variation. Moreover, each axis of variation represents a continuum where every variety dissolves into another (Berruto 2007). Since the axes intersect, the Italian repertoire is usually considered a multidimensional continuum of continua (Grassi et al. 1997). This multifaceted situation can be explained historically (cf. Cerruti et al. 2017). The prolonged contact between Italo-Romance dialects (derived from Vulgar Latin) and what became Italian, created varieties of Italian on the diatopic axis (Crocco 2017, p. 91): Regional Italians (henceforth RI) originated. RIs are varieties of Italian spoken in specific geographical areas of the peninsula, whose differentiating features mainly come from local dialects (Grassi et al. 1997). RIs are, on the one hand, the consequence of what Berruto (2005, p. 83) calls "dialectization of Italian"; on the other hand, the result of the convergence from dialects to Italian (Cerruti 2011). Poggi Salani (2010) suggests that RIs constitute the current spoken Italian. In contrast, Standard Italian is an abstraction without native speakers.

RIs are divided into northern, central, southern and Sardinian varieties (Pellegrini 1977). The southern area is further grouped into high-southern and low-southern, with Calabria overlapping both. Our speakers come from parts of Calabria in the low-southern region. Some phonetic features of Calabrian RI are (cf. De Blasi 2014, pp. 110-11):

- Aspiration of -t-, especially following -r- or -n- (certamente [, Serrt $\left._{\mathrm{r}}^{\mathrm{h}} \mathrm{a}^{\prime} \mathrm{m} \varepsilon n \mathrm{t}^{\mathrm{h}} \mathrm{e}\right]$ 'surely');

- Retroflexion of the cluster -tr-;

- Gemination of intervocalic -b- and -g- (cabina [kab'bi:na] 'cabin', cugino [kud'dzi:no] 'cousin');

- Voicing of plosives after nasals (tanto ['tando] a lot);

- Epenthesis in consonant clusters (aritmetica [, arite'me:tika] 'arithmetic').

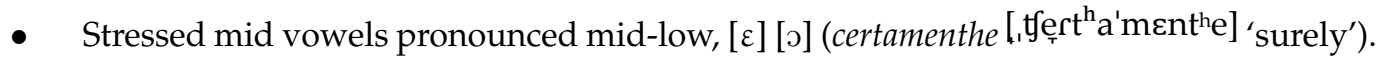

The interviews with speakers of Calabrian origin contain these traits, together with other phonetic, morphosyntactic and lexical traits featured in Calabrian dialects (e.g., $c i$ attualizzante or 'emphatic $c i$ '-ci 'there' before the verb avere 'to have' for emphasis; dialectal articles; dialectal words such as ammucciare 'to hide'; and confusion between imparare 'to learn' and insegnare 'to teach'). Examples 1-3, below, from our corpus, illustrate phonetic details:

1. Una volta una signora ha detto: "Voglio assaggiare il pranzo che avete fatto." 


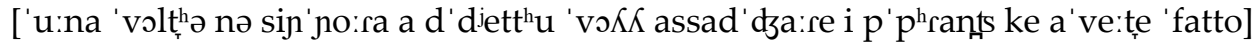

'Once a lady told me: "I want to taste the meal you have prepared."' [I1F73A, 18:42]

2. I genitori avevano un pezzo di terra, la campagna, ma io stavo al paese, andavo a insegnarmi l'arte di falegname, di muratore.

[i ddseni't to:rə ə'və:vno um 'petts di 'terrə la kam' panna ma 'i:o 'sta:vo al phăe:sə ən' da:va a intsen'narmi l ' arthe di falen'na:me di mura' to:re]

'His parents had a piece of land, the farmland, but I stayed in town, I was learning the craft of woodworking, of bricklaying.' [ I1M62A, 21:28]

3. Diciamo che mi sono ... oltre allo studio fatto un pochino di casini là, no, mi sono occupato di vita d'associazione, ne avev-ho creato un'associazione studentesca.

[di'dza:mo kə m 'so:no 'olț 'allo 'stu:djo o f' fatt m po'kiįnə di di di ka'si:nï lla no mə 'ss:no okk h' pa:to dị 'viitta d as, sotfat'tsjone $n$ a've:o o kkre'a:t 'u:na assodzə'zjo:nə studen' theska]

'Let's say I ... In addition to studying, I've made a bit of a mess, there, you know, I've handled club life, I had- I've created a student club.' [IXM35A, 20:44]

The convergence of a group of dialectal traits onto a base still recognizable as Italian allows us to identify what we have elicited as Calabrian RI, although these traits are present to different degrees across speakers. As the literature claims (cf. Grassi et al. 1997; Cerruti 2011; Crocco 2017; Section 2.2), the rate of perceived 'regionality' varies within the RI. One conditioning factor is how much 'regionality' is valued across the community of speakers. We examined speakers from southern Calabria (primarily Vibo Valentia), and their local varieties remain subject to stigma today, affecting this sense of belonging. Nodari's (2017) review of linguistic autobiographies of Calabrian teenagers shows that parents today do not directly teach dialects and often scold their children for using them. Several participants describe their local variety negatively or report that teachers punish those who use it at school. Some teens feel shame in admitting knowing their dialect. Despite this, dialect is used among peers in informal, everyday contexts.

\subsection{Final Vowel Phenomena}

We distinguish two phenomena that affect final vowels in Italian varieties: reduction and apocope, or deletion. An Italian word with a full-timbre final vowel, like [bam 'bi:no] 'child', can be produced with the final vowel reduced, [bam 'bi:nə], or deleted, [bam 'bi:n]. Some studies claim that reduction and apocope are stages of a single process, with the former being a step toward the latter (cf. Section 2.1.2). We summarize each phenomenon in turn. Final vowel reduction is reported to be typical of high-southern Italian varieties, with some research mentioning deletion there too. As studies attest it also in low-southern varieties (cf. Section 2.1.1), we expect our speakers to show variability.

\subsubsection{Reduction}

'Reduction' can include any type of decrease in the difficulty, quantity, or size of the articulatory movements required for the realization of a phone. The relevant type of reduction is centralization: the articulation of a vowel in a more central area of the vowel space.

While final vowels in Standard Italian are traditionally considered to be full-timbre, many studies demonstrate the contrary, showing centralization and reduction of duration in every RI and style (cf. Albano Leoni et al. 1995; Fava and Caldognetto 1976; Savy and Cutugno 1997). In fact, the tendency that these studies attest may well be universal (Vayra 1991). Nevertheless, Marotta and Sorianello (1998) claim that final vowel reduction is subject to diatopic and substrate factors that modify its intensity in different parts of Italy. In other words, every speaker tends to reduce when using the everyday variety (RI), some speakers more than others, and this may be due to the influence of the local dialect. In fact, descriptions of RIs (De Blasi 2014; Vietti 2019) note reduction only in RIs whose corresponding dialect also has it. Considering the corresponding dialect to glean 
information about the RI is justified, since, according to Telmon (1993, p. 96), the dialect is the clearest means to understand and interpret the RI. Even though we cannot know a priori which dialectal features will be found in the corresponding RI, we hypothesize, based on this claim, that higher rates of final vowel reduction will be observable in the RI of speakers whose dialect presents the phenomenon.

Therefore, let us turn to Calabrian low-southern dialects, to see if traces of final vowel reduction, potentially transmittable to RI, can be found. While Calabrian low-southern dialects do not traditionally present centralized unstressed vowel systems (Loporcaro 2009), experimental work shows otherwise. Trumper et al. (2001) assert that Calabrese presents both centralization and notable duration reduction in post-tonic vowels. Romito et al. (1997) and Loporcaro et al. (1998) experimentally attest final atonic vowel centralization for the dialects of the extreme South of Calabria. Romito et al.'s study Crotonese and postulate a synchronic variable rule that operates in that dialectal system: final atonic vowels /i, a, $u$ / $\rightarrow[\ni]$, with the centralization varying depending on speech style. Loporcaro et al. describe this rule as a step towards the creation of a phonological /ə/ in Southern Calabrese.

Dialect may not be the only source of reduction in Calabrian RI: "Regiolects may develop linguistic innovations of their own which have no basis in the standard variety, nor in the dialects" (Auer 2005, p. 31) and "The dialectal substrate is not the only element capable of explaining RI" (Cerruti 2009, p. 31). Furthermore, despite the aforementioned studies, the status of final vowel reduction in Calabria is still ambiguous, empirically. More diachronic and/or apparent time data on both dialect and RI are needed, and there is no clear empirical evidence to determine whether the phenomena described in the literature are ongoing innovations or established patterns (and, if so, since when). Thus, we are interested in seeing whether Calabrian RI presents final vowel reduction, leaving to other works the problem of understanding the origins of the phenomenon.

Considering reduction more broadly, some factors known to influence it are discussed: Van Bergem (1994) mentions lexical frequency and the phonemic context of the vowel. These factors are significant in Romano and Manco's (2003) study of vowel reduction in the varieties of Bari and Lecce (Apulia), and Bybee (2003) notes that high lexical frequency can lead to reduction phenomena. In Beckman's (1996) work on Montreal French, reduction of high vowels occurs especially after fricatives. With regard to vowel identity, Farnetani and Busà (1999) test Italian final vowel reduction and show that /a/ and /o/ tend to maintain a longer duration than (in order of length) /e/, /u/ and /i/. Additionally, Romito et al.'s (1997) study of the Crotonese dialect points out a smaller degree of centralization for /a/—which remains distinct from schwa-than for /i/ and / u/. Silvestri's (2018) analysis of north-western Calabrian varieties also shows that final atonic /a/ is the only vowel not neutralized. Finally, Voghera (2001) notes that vowel reduction can also affect segments that are morphological markers: she reports a study by Savy (1999a, 1999b) which highlights the deletion of morphological suffixes. While this list is not exhaustive, it pertains to factors that can specifically be tested in a corpus of spontaneous speech (i.e., excluding stylistic variation).

\subsubsection{Deletion}

We first distinguish variable apocope from categorical apocope. The latter is a process that eliminates sequences of vowels across a word boundary. It affects all Italian varieties including Standard Italian. Categorical apocope, according to Nespor (1990), includes elision (la elica > l'elica, 'the propeller'), vowel degemination (erano orridi > èranòrridi, 'they were horrible') and specifier vowel deletion (quell'albero (« quello), 'that tree'). All such contexts are excluded from our dataset so that we can focus on variable apocope in other (preconsonantal) contexts.

Turning to variable apocope, Russo and Barry (2002) assert that the deletion of the centralized vowel corresponds to the final stage of a weakening process. Farnetani and Busà (1999) similarly see apocope in Italian as "the endpoint of gradient articulatory reduction rather than the outcome of phonological rules". If we once again seek clues 
in the dialect for what may happen in RI, we find some studies claiming that apocope has started to affect dialects that previously only showed reduction. Examples are the dialects of Naples (cf. Albano Leoni 2015; Maturi and Mastantuoni 2012; Cristiano 2019; Radtke 1997; Rohlfs 1966), Apulia and Lucania (Loporcaro 1988; Romano 2020), Ischia and Pozzuoli (Russo and Barry 2002) and North-Western Calabria (Silvestri 2018). We can thus conclude that centralization and apocope might well be connected. The former affects the quality of vowels, while the latter affects their duration. We expect that dialects such as the low-southern Calabrian ones, which already feature centralization and reduction in atonic vowels according to studies cited in Section 2.1.1, may be inclined to (variably) delete the same atonic vowels, and that they may transfer this inclination to their RI.

Let us now list some conditioning factors for apocope. The position of the token seems to be particularly influential. Russo and Barry (2002) include some "standard" contexts for the phenomenon: intonation-phrase final and intermediate phrase boundary. They also link apocope to speaking rate. Loporcaro's (1988) claim (regarding the Altamura dialect) is that final vowel apocope only happens pre-pausally, as the step following reduction. Romano and Manco (2003) hypothesize syntactic and intonational boundaries to be influent for final-vowel deletion too. Maturi and Mastantuoni (2012) also mention pre-pausal position, while adding to the list of influencing factors sociolinguistic features such as age, the relationship of speakers with their variety and communicative context.

Conditioning factors proposed in literature are hence summarized as follows:

- Speaking rate;

- Intonational and syntactic context;

- Social variables.

\subsection{Stylistic Variation}

In spoken language, features from a range of (diastratic and diatopic) varieties may mix, making it difficult to provide exact matches between extracts of spontaneous speech and the named varieties of spoken language reported to exist in Italy. A quick look at the examples from our corpus (1-3, above) show that they contain features connected to both Standard Italian and RI or even dialect. Bell (1984) pointed out that individuals' stylistic variation mirrors interspeaker variation defined by social status. Thus, we expect to find, in a corpus of spontaneous speech recorded in casual contexts, variation that includes forms associated with varieties of lower status. If we compare the descriptions of standard Italian, RIs and dialects, we see that reduction and deletion are associated with the latter but not the former. For heritage speakers, who virtually only use their heritage language in casual contexts, we might expect a higher concentration of these non-standard variations than in a sample elicited in the same way from homeland speakers, who have more exposure to (and, in some cases, use of) Standard Italian. Indeed, Cerruti (2011) proposes the existence of "folk" RI, educated RI, and standard RI, which can presumably all be found in our corpus and likely even produced by a single individual.

As Grassi et al. (1997) and Crocco (2017) state that the rates of local traits in RI depend on social and contextual factors, we anticipate variability in their rates of use across speakers and across linguistic contexts, even when all speakers are speaking the same RI and all speech is elicited in the same context. Thus, our task is to describe how these social and linguistic context factors predict (or are indexed to) the variation between full, reduced and deleted word-final vowels. Careful analysis will reveal whether these processes reflect an ongoing innovation or something already established and, if so, since when.

\section{Research Questions}

The questions we aim to answer are:

- Can we establish systematic patterns of variation in spontaneous speech concerning vowel reduction and apocope?

- What linguistic and social factors constrain the process? Do these differ between homeland (in Calabria) and heritage (in Toronto) speakers? 
- Can we find evidence that relates the processes of vowel reduction and apocope?

To probe these questions, the following hypotheses are tested:

1. We hypothesize that there are differences between older and younger speakers in both the rate and the factors which condition selection between full, reduced and deleted word-final vowels. This is motivated by sociolinguistic expectations that younger speakers exhibit more use of innovative variants than older speakers, allowing us to understand linguistic change through an apparent time lens.

2. Additionally, we predict that heritage speakers exhibit more reduction and more deletion than homeland speakers because their use of Italian is, generally, more restricted to casual (at home) contexts than is the case for speakers in Italy.

3. We further anticipate effects of generation and/or ethnic orientation, as heritage speakers who use Italian more often (than English) or are more oriented toward Italian culture (than Canadian culture) are expected to more robustly maintain features of the homeland variety. Each successive generation of heritage speakers has more opportunities to be immersed in English than the previous one.

4. We also test a series of hypotheses, based on the literature discussed in Section 2, that various linguistic factors (listed in Table 2) affect patterns of deletion and reduction. It is critical to control for variation across linguistic contexts in order to properly measure social factor effects.

\section{Materials and Methods}

The data come from the Heritage Language Documentation Corpus (Nagy 2009, 2011), developed by the Heritage Language Variation and Change in Toronto Project (HLVC, http:/ /ngn.artsci.utoronto.ca/HLVC, accessed on 6 July 2021). We examined 25 recorded and transcribed interviews in Calabrian RI. Speakers are distributed as in Table 1. In the HLVC project, speakers are categorized as follows (Nagy 2015, p. 313):

- Homeland: speaker has always lived in southern Calabria, and has southern Calabrian parents ${ }^{2}$;

- Generation 1 (Gen1): speaker has lived at least their first 18 years in Calabria and has lived in the Greater Toronto Area (henceforth Toronto) for at least 20 years;

- Generation 2 (Gen2): parents qualify as Generation 1 (although they might not be in the corpus) and speaker was either born in Toronto or arrived before age six;

- Generation 3 (Gen3): parents qualify as Generation 2 and speaker was born in Toronto.

Table 1. Speaker distribution.

\begin{tabular}{cccccc}
\hline Gender & Homeland & Gen1 & Gen2 & Gen3 & Total \\
\hline Female & 5 & 2 & 4 & 1 & 12 \\
Male & 6 & 4 & 2 & 1 & 13 \\
\hline
\end{tabular}

Interviews were conducted according to standard sociolinguistic interview protocol (Labov 1984). The interviews were conducted in spaces selected by the participants, often at home, to encourage relaxed conversational speech. Recordings used a Zoom H4n digital recorder (44.1 kHz sampling rate) with an Audio Technica lavalier microphone. Elan (Wittenburg et al. 2006) was then used to create time-aligned transcriptions and code contextual factors.

From these interviews, we analyzed 2477 tokens. To select tokens, a concordance was constructed from the 25 interviews. From this word list, 18 frequent polysyllabic words were selected. The five most frequent nouns after these were selected as well. All tokens of these words were selected. From this set, contexts of elision and obligatory apocope were excluded. Mixed-effects models were fitted to the remaining data set.

The dependent variable in these models is the form of the final vowel. This variable was impressionistically coded with three levels: Full, Reduced and Deleted. The coders 
are all Italian speakers. Unclear cases of deletion were confirmed by visual examination in Praat. Ambiguous coding decisions were resolved collaboratively by both coders.

We conducted two analyses, each handling these three levels differently, in order to compare the distributions relevant to the two (putatively connected) processes of reduction and deletion. As multivariate analysis using logistic regression requires binary variables, we first combined Deleted and Reduced tokens to create a binary variable: Full vs. Reduced\&Deleted, to examine reduction patterns. In the second analysis, Full tokens were excluded to create a binary variable: Reduced vs. Deleted, to examine deletion patterns.

The linguistic factors we predict to influence this variable, based on the literature discussed in Section 2, are FinalVowel, NumberOfSyllables, Stress, ClausalPosition, WordFrequency, PartOfSpeech, TokenOnsetManner, TokenOnsetPlace, NextWordOnsetManner and NextWordOnsetPlace. The latter four were reduced to ResyllabificationPossible (of the two newly adjacent consonants post-deletion), after examination of their behavior. The levels for each predictor are listed in Table 2.

Table 2. Linguistic factors analyzed and their variants.

\begin{tabular}{|c|c|c|}
\hline Linguistic Factor & Variants & Example \\
\hline \multicolumn{3}{|c|}{ Segmental } \\
\hline \multirow[t]{4}{*}{ FinalVowel } & $\mathrm{a}$ & [bam.'bi.na] '(female) child' \\
\hline & $\mathrm{e}$ & [a.'mi.ke] '(female) friends' \\
\hline & $\mathrm{i}$ & [bam.'bi.ni] 'children' \\
\hline & o & [bam.'bi.no] '(male) child' \\
\hline \multirow[t]{3}{*}{ TokenOnsetManner } & voiceless stop & [a.'mi.ke] '(female) friends' \\
\hline & voiceless fricative/affricate & [,pja.tfe] 'like it' \\
\hline & sonorant & [bam.'bi.na] '(female) child' \\
\hline \multirow[t]{2}{*}{ TokenOnsetPlace } & alveolar & [bam.'bi.na] '(female) child' \\
\hline & non-alveolar & [a.'mi.ke] '(female) friends' \\
\hline \multirow[t]{6}{*}{ NextwordOnsetManner } & voiced/voiceless stop & $\begin{array}{l}\text { erano calabresi 'they were } \\
\text { Calabrian' }\end{array}$ \\
\hline & voiced/voiceless fricative & proprio sopra 'right above' \\
\hline & voiceless affricate or pause & mia famiglia. 'my family' \\
\hline & nasal & diciamo mio 'we say my' \\
\hline & liquid & siamo rimasti 'we remained' \\
\hline & pause & mia famiglia. 'my family' \\
\hline \multirow[t]{4}{*}{ ResyllabificationPossible } & yes & adess $(o)$ l'uomo 'now the man' [sl] \\
\hline & & abbiamo visto 'we saw' $\left[{ }^{*} \mathrm{mv}\right]$ \\
\hline & following pause & abbiamo. 'we have [pause].' \\
\hline & geminate created & $\operatorname{diciam}(o)$ mio 'we say my' $([\mathrm{mm}])$ \\
\hline \multicolumn{3}{|c|}{ Suprasegmental } \\
\hline \multirow[t]{2}{*}{ Stress } & antepenultimate & ['e.ra.no] '(they) were' \\
\hline & penultimate & [bam.'bi.na] '(female) child' \\
\hline \multirow[t]{2}{*}{ ClausalPosition } & final & mia famiglia. 'my family' \\
\hline & nonfinal & mia famiglia è ... 'my family is' \\
\hline \multicolumn{3}{|c|}{ Lexical } \\
\hline WordFrequency & continuous: $34-228$ occurrences & \\
\hline \multirow[t]{4}{*}{ PartOfSpeech } & adjective & proprio 'proper/exact/correct' \\
\hline & adverb & veramente 'really' \\
\hline & noun & bambina '(female) child' \\
\hline & verb & siamo 'we are' \\
\hline
\end{tabular}

Some factors need explanation regarding their purpose in our analyses. The first segmental factor is FinalVowel, the identity of the word-final vowel (that is, the target of apocope and reduction), included due to claims that some vowels are more susceptible to reduction than others (see Section 2.1.1). Place and Manner of both the onset of the final syllable and the onset of the following syllable (in the next word) were coded to investigate 
whether sonority influences the processes (cf. Section 2.1). After examination, these four were reduced to ResyllabificationPossible, a factor that distinguished sequences that form a licit onset cluster if the intervening vowel is deleted vs. those that do not form a licit cluster.

Two suprasegmental factors are considered. Stress indicates which syllable of the token word receives primary stress to determine whether foot structure influences the variable processes. ClausalPosition indicates where the token appears in its clause because, as mentioned in Section 2.1.2, boundaries (both syntactic and intonational) may influence apocope.

Two factors relating to the lexical item are considered. PartOfSpeech of the word was included because studies such as Voghera (2001) and Savy (1999a, 1999b) note the role of morphological markers for reduction. This allows us to investigate if the morphological markers of certain word types are more prone to reduction and/or deletion than others. Word frequency has frequently been proposed to affect reduction processes.

Reduction of levels in many of these factors are required by the analyses, described in Section 4, to produce robust models. This was done by combining levels that are most similar phonologically and in terms of rates of deletion or reduction. The results in the tables in Section 5 indicate the final decisions about which levels are distinguished.

To determine whether the variable pattern of deletion is stable or undergoing change, and whether homeland and heritage speakers apply apocope similarly, we included in the model the social factors generation, age, and gender of the speaker. For the heritage speakers, we also considered a selection of ethnic orientation (EO) scores, each corresponding to averaged, quantified responses from one section of the HLVC Ethnic Orientation Questionnaire. The categories are: Ethnic Identity, Language Choices, Cultural Environment, Language Use, Cultural Choices and Experiences of Discrimination. These cover questions such as how the speakers identify themselves ethnically-in the case of Heritage Italian speakers, whether they consider themselves Italian, Canadian, or Canadian-Italian; if most of their neighbors or their friend group is Italian; what languages they speak and in what contexts; their parents' and grandparents' heritage; and their experiences with Italian culture and discrimination. The questionnaire is posted at http://ngn.artsci.utoronto.ca/pdf/HLVC/short_questionnaire_English.pdf (accessed on 6 July 2021). EO responses are scored on a scale in which " 0 " indicates orientation toward English or Canada, " 2 " indicates orientation toward Italian or Italy, and " 1 " indicates a "both" or "mixed" response. We predict that heritage speakers with higher scores will produce patterns more like homeland speakers.

Homeland speakers' age range is 19-61, with an average age of 45 . The heritage speakers are grouped into three generations (see Table 1). Generations are not defined by age, but age ranges for each generation differ: Generation 1, 61-73 years; Generation 2, 44-57; Generation 3, 21-22. Because age and generation are collinear, separate models are compared, one with generation and the other with age (as a continuous factor).

The tokens, which we code in ELAN, were consolidated with the coding for the speakers' characteristics in a dataframe for analysis. Mixed effects multivariate analyses performed in Rbrul (Johnson 2009) measured the weight of each independent variable, or predictor, on the selection between Full and Reduced or Deleted, and then between Reduced and Deleted, final vowels. Step-up/step-down comparison of models determined the best-fitting models. Models were constructed for the dataset as a whole, and for each generation. These allowed us to compare the factors that predict the reduction and deletion processes in each group.

After testing the linguistic factors and age, gender and generation, the effects of EO were explored. Because EO is not independent of generation and not relevant to homeland speakers, we tested its effect using Spearman ranked-correlation tests to see whether speakers with higher scores also have higher deletion or reduction rates. For this, we used the estimates for Speaker as a random effect from the reported mixed effects models, in order to make comparisons with the effects of differing contextual distributions taken out. 


\section{Results}

We first present the distribution of the three variants: Full, Reduced and Deleted word-final vowels. Figure 1 illustrates the stability of the system: each generational group produces about two-thirds of the word-final vowels as Full, about one-quarter Reduced and 1/10 Deleted. Individual are reasonably similar, in terms of use of full forms: rates range from $81 \%$ to $100 \%$ full forms. Of (the small portion of) non-full forms, speakers range from $47 \%$ to $86 \%$ reduced (deleting the balance of the vowels).

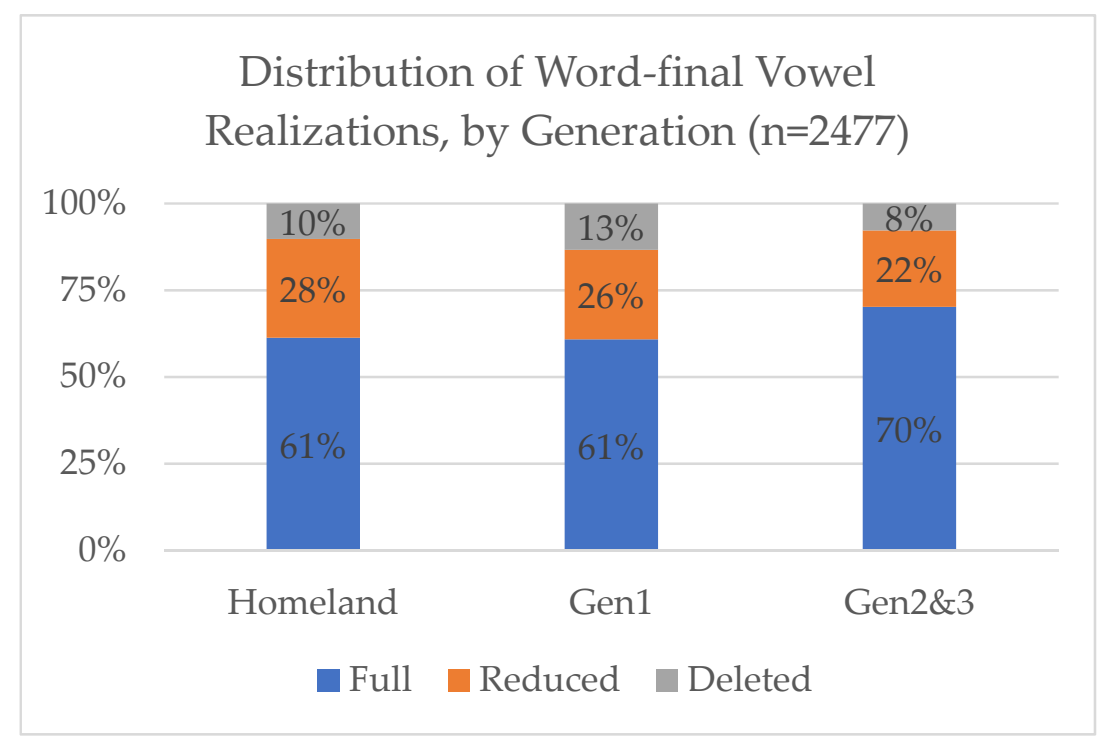

Figure 1. Distribution of vowel realizations by generation.

As confirmed statistically below, there is an age effect for deletion, but not reduction: younger speakers are less likely to delete final vowels. This is illustrated in Figure 2, which shows a difference of $11 \%$ in the rate of full forms (from $55 \%$ for the oldest group to $66 \%$ for the youngest), but only an $8 \%$ difference for the rate of Deleted forms. We are not sure why these putatively related processes don't change over apparent time in a more synchronized way, but perhaps the second stage (deletion) is too recent and not yet regularized in parallel with reduction. Alternatively, our models may be missing relevant predictors.

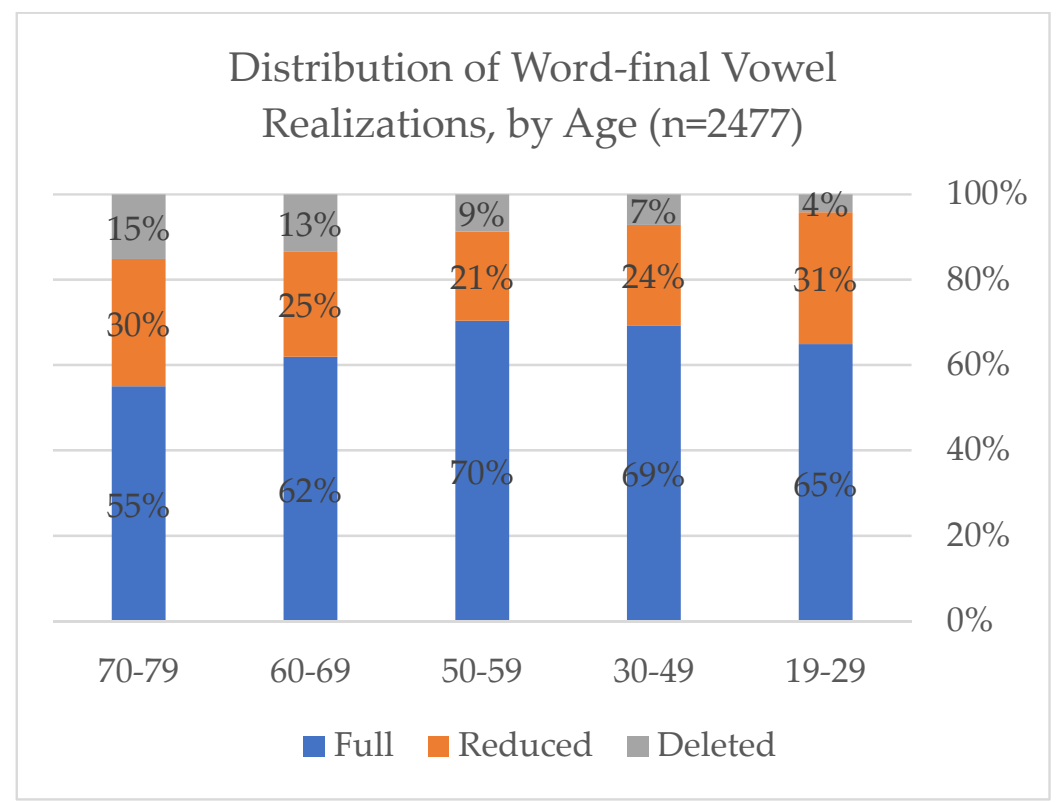

Figure 2. Distribution of vowel realizations by age. 


\subsection{Full vs. ReducedEDeleted Comparisons}

We next compare mixed effects models with various predictors of the form of the final vowel, presenting the models that best fit the distribution of the data. We first consider binary models that contrast the Full form (application value) against the Reduced and Deleted forms (non-application values), to examine the reduction process. Models fit via step-up/step-down comparison indicate that the predictors of production of Full vowels relate to the resyllabifiability of the newly-formed cluster (if the vowel indeed deletes), Stress, Part of Speech and Age. The strongest effect (range $=31$ ) is that Full forms are favoured unless a geminate is created. Full forms are favoured more by Antepenultstressed words than Penult-stressed, and more by Adverbs, Adjectives, and Nouns than by Verbs. The effect of age is that the older the speaker, the less they favour full forms, as seen in Figure 3. All other factors listed in Table 2 were tested but not found significant in this best-fitting model. Notably, generation did not emerge as significant in models that included it in place of age. Table 3 reports a model with centered factor weights, and range calculated as the difference between the highest and lowest factor weight $(\times 100$, by convention). Speaker is included as a random effect and shows that individuals vary from 80-96\% Full forms (after excluding five speakers who only produced Full forms).

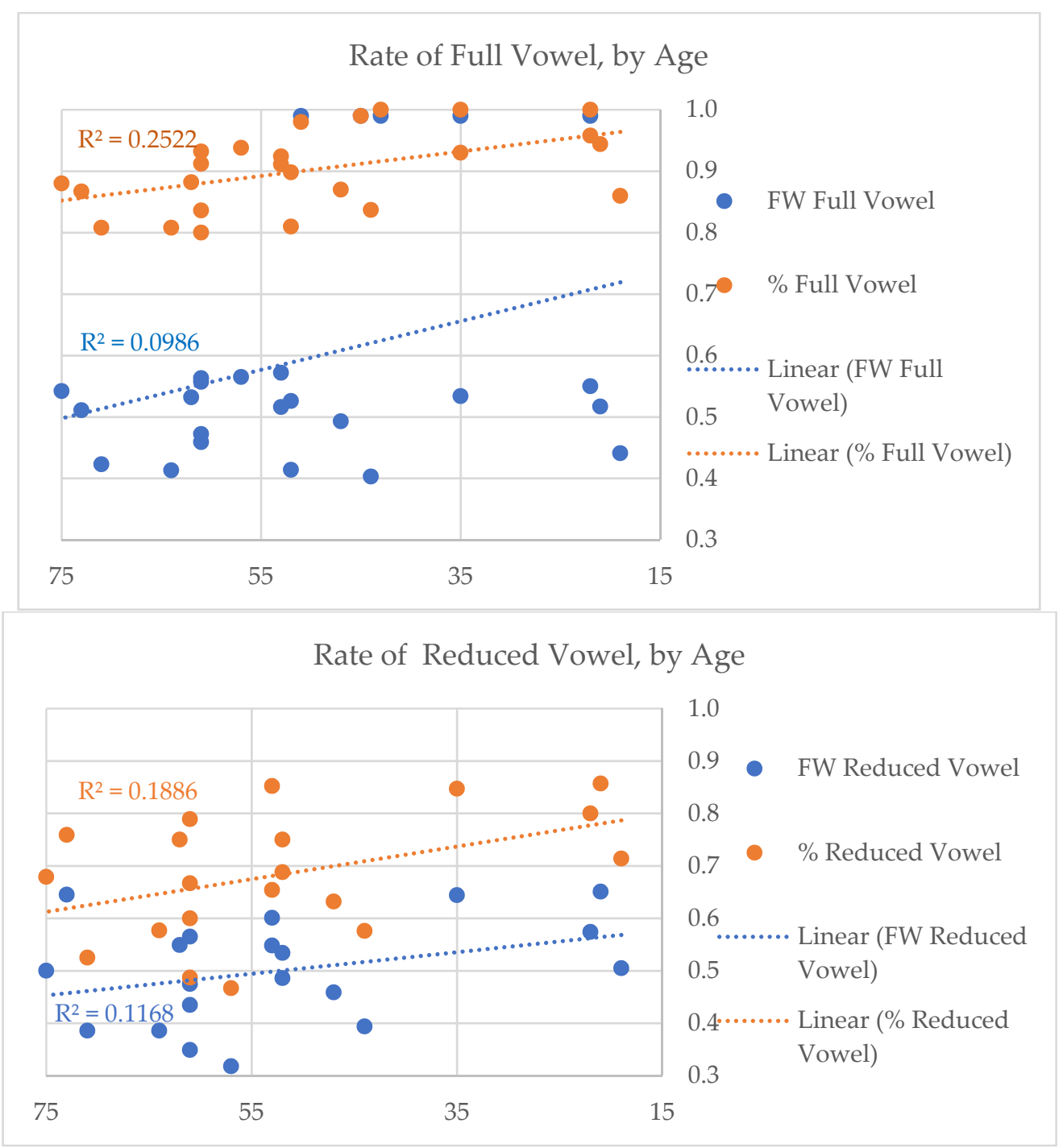

Figure 3. Scatterplots of Speakers for rate of Full vs. Reduced\&Deleted (top, $n=2477$, of which 2189 included in model) and Reduced vs. Deleted (bottom, $\mathrm{N}=815$ ). Speakers' age is on the $x$-axis. 
Table 3. Best-fitting mixed-effects model with Full Vowel as application value and Reduced\&Deleted as non-application value, for all speakers $(\mathrm{N}=2189)$.

\begin{tabular}{|c|c|c|c|c|c|}
\hline Predictor & Logodds & $\mathbf{n}$ & $\begin{array}{l}\text { \% Full } \\
\text { Vowel }\end{array}$ & $\begin{array}{l}\text { Factor } \\
\text { Weight }\end{array}$ & Range \\
\hline \multicolumn{6}{|c|}{ Resyllabification Possible $(p<0.001)$} \\
\hline Pause follows & 0.412 & 455 & $91 \%$ & 0.60 & \\
\hline Yes & 0.349 & 71 & $92 \%$ & 0.59 & 31 \\
\hline No & 0.111 & 1568 & $88 \%$ & 0.53 & \\
\hline Geminate created & -0.872 & 95 & $76 \%$ & 0.30 & \\
\hline \multicolumn{6}{|l|}{ Stress $(p<0.001)$} \\
\hline Antepenult & 0.299 & 514 & $92 \%$ & 0.57 & 15 \\
\hline Penult & -0.299 & 1675 & $87 \%$ & 0.43 & \\
\hline \multicolumn{6}{|c|}{ Part of Speech $(p<0.001)$} \\
\hline Adverb & 0.207 & 450 & $90 \%$ & 0.55 & 14 \\
\hline Adjective or Noun & 0.157 & 898 & $91 \%$ & 0.54 & \\
\hline Verb & -0.364 & 841 & $85 \%$ & 0.41 & \\
\hline \multicolumn{6}{|l|}{ Age $(p=0.04)$} \\
\hline continuous & -0.015 & & & & \\
\hline
\end{tabular}

As Farnetani and Busà's (1999) descriptions of Italian apocope report patterns depending of the identity of the final vowel, we report this distribution in Table 4, though it does not have a significant effect in our analyses. (Vowel emerges as a significant predictor of Reduction if Stress is excluded from the model, but Stress produces a better-fit to the data.)

Table 4. Distribution of surface forms by final-vowel identity $(\mathrm{N}=2477)$.

\begin{tabular}{ccccc}
\hline Dependent Variable (3 Levels) & i & e & o & a \\
\hline Deleted & $11 \%$ & $13 \%$ & $12 \%$ & $6 \%$ \\
Reduced & $19 \%$ & $21 \%$ & $19 \%$ & $44 \%$ \\
Full vowel & $70 \%$ & $65 \%$ & $70 \%$ & $50 \%$ \\
\hline
\end{tabular}

We next compare models for the homeland, Gen1 and Gen2/Gen3 speakers in order to determine whether the same grammar determines the selection of Full vs. Reduced word-final vowels in each. (One of our two Gen3 speakers categorically produces full vowels, so the one remaining Gen3 speaker is combined with Gen2.) In these models with fewer tokens than the model of all speakers shown in Table 1, fewer factors emerge as significant. Rather than showing the full models, we note only which factors are significant for each speaker group. Table 5 shows an increase in the complexity of the factors governing reduction: homeland speakers are governed by one (lexical) factor, while heritage speakers are governed by that factor plus a phonological factor. Levels are ranked similarly across models for each generation.

Table 5. Significant predictors (indicated with " $\checkmark$ ") in MEMs comparing Full vs. Reduced\&Deleted vowels, for each speaker group.

\begin{tabular}{ccccc}
\hline Predictor & All Speakers & Homeland & Gen 1 & Gen 2/3 \\
\hline n & 2189 & 644 & 860 & 685 \\
\hline Part of Speech & $\checkmark$ & $\checkmark$ & $\checkmark$ & $\checkmark$ \\
Resyllabification possible & $\checkmark$ & & $\checkmark$ & \\
Stress & $\checkmark$ & & & \\
Age & $\checkmark$ & & \\
\hline
\end{tabular}




\subsection{Reduced vs. Deleted Comparisons}

We turn next to a comparison of reduction vs. deletion. In the following models, tokens with full vowels are excluded in order to focus on the alternation between reduction and deletion (which were combined in the non-application value in Section 5.1). The application value is Reduction. Again, we first consider the patterns in the full speaker sample, shown in Table 6. The same three linguistic factors that were significant in the choice between Full vs. Reduced\&Deleted are significant here, with Resyllabification again playing a large role. Reduction is disfavoured (in comparison to Deletion) if the deletion introduces a licit cluster or geminate. However, differing from the models of Full vs. Reduced\&Deleted, age is not significant here.

Table 6. MEM for all speakers together, comparing Reduction to Deletion $(\mathrm{N}=815)$.

\begin{tabular}{cccccc}
\hline Predictor & Logodds & $\mathbf{n}$ & \% Reduced & $\begin{array}{c}\text { Factor } \\
\text { Weight }\end{array}$ & Range \\
\hline Resyllabification possible & $(p<0.001)$ & & & & \\
Pause follows & 0.539 & 147 & $74 \%$ & 0.63 & 32 \\
No & 0.467 & 607 & $69 \%$ & 0.62 & \\
Yes & -0.225 & 17 & $65 \%$ & 0.44 & \\
Geminate created & -0.781 & 44 & $48 \%$ & 0.31 & \\
\hline Part of speech $(p<0.001)$ & & & & & \\
Adverb & 0.543 & 191 & $76 \%$ & 0.63 & \\
Adjective or Noun & 0.259 & 344 & $77 \%$ & 0.56 & \\
Verb & -0.802 & 280 & $54 \%$ & 0.31 & \\
\hline Stress $(p<0.001)$ & & & & & \\
Antepenult & 0.348 & 186 & $76 \%$ & 0.59 & \\
Penult & -0.348 & 629 & $67 \%$ & 0.41 & \\
\hline
\end{tabular}

Next, we compare models for each speaker group, to determine how the grammars governing reduction vs. deletion differ across generations, summarized in Table 7.

Table 7. Significant predictors (indicated with " $\checkmark$ ") in MEMs comparing Reduced vs. Deleted vowels, for each speaker group.

\begin{tabular}{ccccc}
\hline Predictor & All Speakers & Homeland & Gen 1 & Gen 2/3 \\
\hline $\mathrm{n}$ & 815 & 261 & 337 & 217 \\
\hline Part of speech & $\checkmark$ & $\checkmark$ & $\checkmark$ & $\checkmark$ \\
Resyllabification possible & $\checkmark$ & $\checkmark$ & & \\
Stress & $\checkmark$ & & & \\
Age & & & \\
\hline
\end{tabular}

Unlike the pattern in Table 5, for Reduction vs. Deletion, we see a simplification of the grammar when we compare heritage speakers (governed only by one lexical factor) to homeland speakers (governed by that same factor plus the Resyllabification factor). This may be indicative of some reanalysis of how both processes work. Alternatively, these smaller samples of available tokens may not support robustly representative models. However, within each significant factor, levels are identically ordered.

\subsection{Age Effects in Reduction and Deletion}

Let us consider the effect of Age more closely. Recall that Age is significant for the analysis of Full vs. Reduced\&Deleted forms, but not for the analysis of Reduced vs. Deleted forms. This is unexpected if Deletion is the final stage of the reduction process. Figure 3 contains scatterplots of individual rates for both processes. In the top plot, the orange dots indicate the percentage of tokens that are Full (vs. Reduced\&Deleted). In the bottom plot, they indicate the percentage of tokens that are Reduced (vs. Deleted). Blue dots indicate 
Speaker random effect estimates for these same application values. Speakers are arranged from oldest to youngest (left to right). Speakers who categorically produce the application value are shown at 100\% and with a factor weight of 1.0 (but they were not included in the regression analyses). Including them here provides a more realistic picture of the age effect. The slopes for the two processes are similar: younger speakers produce more Full as well as more Reduced forms. This fuller picture, including categorically Full-vowel speakers, contradicts the models described above, where Age was a significant predictor only for Full vs. Reduced\&Deleted. The lack of a significant age effect for the second stage of the process may be due to the smaller sample size. In "real life," speakers have much larger samples to calibrate to, and this difference between the two processes would be less stark.

\subsection{Ethnic Orientation (EO)}

As quite a bit of inter-speaker variation is unaccounted for in the models above, we seek explanation in "ethnic orientation". As described in Section 4, the Ethnic Orientation Questionnaire elicited self-reports on how speakers orient to their Italian ethnicity, their language preferences and practices, their cultural preferences and practices and whether they have been subject to discrimination as Italians. As these responses are not independent of each other, we separately examine the correlation of each factor to speakers' rates of reduction and deletion, using the estimates calculated for Speaker as a random effect in the models for all speakers reported above (Tables 3 and 6). For the choice between Full vs. Reduced\&Deleted, one set of responses is correlated both significantly and strongly: Discrimination. This is a combined score for the following questions, where higher scores reflect experience of discrimination of this type:

- Have you ever had a problem getting a job because you're Italian?

- What about renting an apartment or buying a house?

- Were you treated differently by your teachers in school?

- Have you ever been treated badly because you're Italian?

- Is there a lot of discrimination against Italians?

For the choice between Reduced vs. Deleted, a different factor is correlated significant: speakers' orientation. This factor is composed of responses to these five questions, where higher scores reflect orientation toward their Italian ethnicity:

- Do you think of yourself as Italian, Canadian or Italian-Canadian?

- Are most of your friends Italian?

- Are people in your neighborhood Italian?

- Are the people you work with Italian?

- When you were growing up, were the kids in your school Italian? Were your friends? The kids in your neighborhood?

This suggests that speakers' orientation toward their culture, and resulting discrimination, are more connected to their speech production than the expected factors, such as how often they use the language or actually engage in cultural activities with other Italians.

These analyses, using Spearman's rank correlation $\rho$, are summarized in Table 8. As has been reported for other variables examined in this same corpus of Heritage Italian data (Nagy 2018), there is little relationship between ethnic orientation factors and linguistic variation. 
Table 8. (Non-)correlation of ethnic orientation to apocope and reduction in Heritage Italian (13 speakers).

\begin{tabular}{|c|c|c|c|c|c|c|}
\hline & $\begin{array}{l}\text { Ethnic } \\
\text { Identity }\end{array}$ & $\begin{array}{c}\text { Lg. } \\
\text { Choices }\end{array}$ & Cult. Env. & Lg. Use & $\begin{array}{c}\text { Cult. } \\
\text { Choices }\end{array}$ & Discrimination \\
\hline \multicolumn{7}{|c|}{ Full vs. Reduced\&Deleted } \\
\hline$p$-value & 0.21 & 0.41 & 0.74 & 0.70 & 0.96 & 0.01 \\
\hline$\rho$ & 0.39 & 0.26 & 0.11 & 0.12 & 0.01 & -0.70 \\
\hline \multicolumn{7}{|c|}{ Reduced vs. Deleted } \\
\hline$p$-value & 0.03 & 0.29 & 0.65 & 0.22 & 0.11 & 0.48 \\
\hline$\rho$ & 0.66 & -0.35 & -0.15 & -0.40 & 0.51 & -0.24 \\
\hline
\end{tabular}

\section{Discussion}

Surprisingly, our expectation of differences between younger and older speakers is only partially supported. For the rates of both reduction and deletion, we see that age is significant for the alternation between full vs. non-full forms. This is apparent-time evidence of a change in progress. ${ }^{3}$ Age, however, may not be a conditioning effect for the alternation between reduction and deletion.

Interpreting the factors conditioning the two processes, we detect small changes from generation to generation in the grammar governing patterns of vowel reduction. We see an increase in the number of constraints affecting the alternation between Full and Reduced\&Deleted forms, but a reduction for the constraints governing Reduced vs. Deleted forms. Several factors motivated by the literature turned out not to significantly affect this variation: Vowel Identity, ClausalPosition and Lexical Frequency. Place and Manner of the onset consonants turn out not to model the data as well as a combined Resyllabification factor. However, it remains to be explained why Full forms are favored similarly by contexts that do and do not create licit resyllabified clusters, and only disfavored if a geminate would be the result.

Turning to our second hypothesis, we expected the heritage speakers to reduce/delete more than homeland speakers because of assumed restrictions on their use of Italian to informal contexts. Since we do not, in fact, find inter-generational differences in frequency, our results might be interpreted in different ways. We could conclude that Reduction\&Deletion rates in one fixed context (the sociolinguistic interview) are not influenced by the overall frequency of use of the variety.

We must also, however, consider the differences in the conditioning effects. Homeland speakers have more linguistic constraints on Deletion (vs. Reduction) than heritage speakers. We are tempted to suggest that this reflects social differences. As noted in Section 2, Calabrian varieties can be subject to negative social evaluation. In order to avoid stigma, homeland speakers may orient their speech away from dialectal variants, using them in a more restricted number of contexts - both linguistic and extralinguistic. That is, there are contexts to which homeland speakers limit their deletions, but these constraints are not transferred to heritage speakers. Such restrictions by the homeland might persist unconsciously even in informal contexts in which dialectal variants are expected. Heritage speakers may have a different attitude towards dialects and dialectal variants, showing appreciation for the dialect as part of their unique cultural identity. Consequently, they do not manifest the same preference for prestigious variants, resulting in less restrictions and more "freedom" in the way they speak, and therefore, in a less constrained grammar of Reduction\&Deletion. However, it is hard to align this with the lack of difference in rates between these groups.

We not only anticipated effects linked to generations among the heritage speakers, but also to ethnic orientation. However, the alternation between Full vs. non-full forms is governed by only one EO factor, as is the alternation between Reduced vs. Deleted forms. This suggests that attitudes and beliefs towards the community might indeed be connected to speech production, providing additional support for our interpretation of the decrease in constraints discussed in the previous paragraph. 
Critically, our data do not support any attrition-based account, as we do not see significant rate differences based on generation or the EO scores related to language use-two factors that should correlate to deterioration of the grammar as a result of decreasing exposure. Since later generations have more exposure to English (and in more and more contexts), one could expect English to influence their heritage language production increasingly. We must equally reject any account attributing variation to English influence. That is, if any English pattern of reducing unstressed vowels were being adapted by Heritage Italian speakers, then we would expect to see this more frequently in the speakers with more contact with English, but we do not.

Our fourth set of hypotheses about linguistic factors affecting patterns of deletion and reduction have been partially confirmed, with a consistent set of factors affecting both processes. PartOfSpeech has a surprisingly consistent effect, and Resyllabification a partially unexplainable one, for now. The consistent effect of more Full forms, and then more Reduction, for Antepenultimate-stressed words than Penult-stress words indicates that foot structure must be considered in any phonological analysis of the processes, and more broadly, that these are indeed phonological processes.

We consider next the lack of effect of the identity of the final vowel. This may be due to an accident in the structure of our dataset: all words ending in /e/ or /i/ have penultimate stress. This means that Stress and Vowelldentity cannot be included in the same model. While Stress produces a better-fitting model, it does not mean that there is no secondary role for the identity of the vowel. Indeed, Table 4 shows sizable differences among vowels, particularly for reduction rates. If the results actually reflect a situation where vowels undergo reduction or deletion depending on their identity, the greater resistance of $/ \mathrm{a} /$ to reduction and deletion phenomena described in Section 2.1 would be partially confirmed, since our dataset only shows $6 \%$ deletion for /a / (Table 4 ). However, we find $44 \%$ reduction for /a/, countering Silvestri's (2018) report for North-Western Calabrese, which says there is no centralization for this vowel.

Having considered the effects of the linguistic predictors, we can consider a final goal of this study: to establish an empirical link between reduction and deletion, as proposed in the literature (Section 2.1). The outcome is ambiguous. We expected the conditioning effects of the two phenomena to be similar, since the linguistic frame of the process should not change. The more similarities between the patterns, the more connected reduction and deletion would be. Comparing Tables 5 and 7 shows that the significant predictors are the same for the two phenomena. The hierarchy of constraints (ranking of factors by effect size and ranking of levels within each factor by rate of favouring the process) is quite similar. If we consider only linguistic factors, we can confirm that reduction and deletion are part of the same process. What is interesting is that social factors suggest otherwise. If apocope is the endpoint of the reduction process, it should be subject to the same social constraints as reduction. We would expect older speakers to exhibit less reduction, just as they exhibit less Reduction\&Deletion, than younger speakers. However, Table 5 shows, this is not the case: age is not a significant factor in the alternation between Reduced vs. Deleted forms. Perhaps the second stage of the process-deletion-is too recent and not yet regular.

Finally, this study has the added bonus of shedding light on previous findings on apocope in Faetar. Faetar is a Francoprovençal isolate spoken in Apulia, a province not far from Calabria geographically and sharing many linguistic features including both apocope and centralization (De Blasi 2014; Marcato 2007; Loporcaro 2009). Nagy and Bill (1997) illustrate that Faetar is undergoing change in apocope and conclude that it is due to the influence of Italian stress patterns competing with Francoprovençal tonic-final phonotactics (cf. Francoprovençal tonic final syllable, e.g., pan [,pan] 'bread' vs. Italian (ante-) penultimate tonic pattern, e.g., pane [,pa.ne] 'bread'). Until now, no quantitative studies of apocope in Italian varieties in or near Apulia were available for comparison. The present report shows a similar pattern of phonological conditioning and age as a significant predictor, in a variety without a Francoprovençal substrate. Thus, it may be a more widespread Italian variable, rather than conflict between Francoprovençal and 
Italian phonotactics, or perhaps both in tandem, that best account for the distribution reported for Faetar. We hope, in future research, to show that the OT analysis with "floating constraints" (Reynolds 1994) can apply to both these varieties. An important test of a theoretical construct developed for one data set is that it can equally account for another.

\section{Conclusions}

This paper has examined two stigmatized variable phonological processes associated with a regional variety. This study provides empirical evidence that Reduction and Deletion both exist in the RI spoken in southern Calabria. It is the first sociolinguistic analysis that applies variationist methods to establishing the relative effect of multiple linguistic and social factors on these processes.

While the literature suggests that, over time, reduction (vowel centralization) is leading to apocope (deletion of these same word-final vowels), we find an apparent-time effect only for the rate of Reduction\&Deletion (vs. Full), but not for Reduction vs. Deletion, and we find an age effect only for speakers living in Calabria, not for their descendants living in Toronto and speaking Heritage Italian. We find different linguistic effects governing the heritage vs. the homeland variety. In spite of the reduced set of registers in which heritage speakers use their heritage language, we do not find a difference in the rate of use of the less-standard variants either between homeland and heritage or among heritage generations.

However, our models of the two processes provide empirical support for the connection between reduction and deletion: the same set of factors, ranked in virtually the same constraint hierarchies, govern the two processes. The distribution also supports several claims about environmental conditioning that had not previously been quantitatively tested in spontaneous speech.

Many analyses of heritage languages, when based on spontaneously-produced speech and multivariate analysis techniques, show strong similarities, or even identity, with homeland varieties (Nagy 2018). When it comes to Italian apocope and reduction, we see an extension of this trend, in terms of the rates of each variant of final atonic vowels: generation does not emerge as a significant predictor in any model. However, as with the one other variable with socioindexicality in the homeland variety that has been examined in this corpus, VOT of unstressed syllable onsets (Nagy and Kochetov 2013), we find small differences in the constraint hierarchies between heritage and homeland speakers, suggesting that socially-indexed aspects of the language weaken in successive heritage generations. The virtually complete lack of social conditioning for apocope and deletion add to this trend. However, we must keep in mind that, in spite of the stigma associated with southern Italian varieties, we were not able to establish social conditioning in the homeland variety either, with the exception of an effect of age.

Author Contributions: Conceptualization and methodology were developed by all authors. Data was coded by A.B. and A.C. and formal analysis conducted by N.N. The three authors collaboratively drafted and edited all sections of the paper, under N.N.'s supervision; funding acquisition, N.N. All authors have read and agreed to the published version of the manuscript.

Funding: This research was funded by SSHRC, grants number 410-2009-2330 and 435-2016-1430.

Institutional Review Board Statement: The study was conducted according to the guidelines of the Declaration of Helsinki, and approved by the Institutional Review Board of The University of Toronto (protocol code 24041, approved 30 April 2009).

Informed Consent Statement: Informed consent was obtained from all participants involved in the study.

Data Availability Statement: The data presented in this study are available on request from the corresponding author. The data are not publicly available due to confidentiality restrictions.

Acknowledgments: We are extremely grateful to the many students and research assistants who collected, transcribed, analyzed and interpreted the data used in this study and particularly to 
Rachel Keir who co-authored the pilot investigation on which this study is based. They are listed at http://ngn.artsci.utoronto.ca/HLVC/3_2_active_ra.php and http://ngn.artsci.utoronto.ca/HLVC/ 3_3_former_ra.php (accessed on 6 July 2021). We thank the editors and reviewers for help clarifying our findings.

Conflicts of Interest: The authors declare no conflict of interest.

\section{Notes}

$1 \quad$ Speakers are identified by speakercode. "I" identifies the Italian HLVC corpus. The second character identifies the speaker's

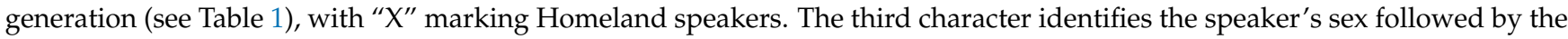
speaker's age. The final character is a unique identifier.

2 Seven speakers live in Vibo Valentia and one in Zumpano (CS).

3 It might, alternatively, be age-grading, but then we expect effects tied to age divisions like in- vs. post-workforce age for a stylistically-important variable.

\section{References}

Abete, Giovanni. 2011. I Processi di Dittongazione nei Dialetti dell'Italia Meridionale. Un Approccio Sperimentale. Roma: Aracne.

Albano Leoni, Federico. 2015. <Carmniell o'srngar>. Osservazioni sulla ortografia ingenua del napoletano e sulle sue possibili implicazioni fonetiche. In Elaborazione Ortografica delle Varietà non Standard. Esperienze Spontanee in Italia e all'estero. Edited by Silvia Dal Negro, Federica Guerini and Gabriele Iannacarro. Bergamo: Bergamo University Press/Edizioni Sestante, pp. 51-78.

Albano Leoni, Federico, Francesco Cutugno, and Renata Savy. 1995. The Vowel System of Italian Connected Speech. Proceeding of the XIIIth International Congress of Phonetic Sciences 4: 396-99.

Auer, Peter. 2005. Europe's Sociolinguistic Unity, or: A Typology of European Dialect/Standard Constellations. In Perspectives on Variation. Sociolinguistic, Historical, Comparative. Edited by Nicole Delbecque, Johan van der Auwere and Dirk Geeraerts. Berlin and New York: de Gruyter, pp. 7-42.

Beckman, Mary E. 1996. When a syllable is not a syllablle? In Phonological Structure and Language Processing, Cross-Linguistic Studies. Edited by Takeshi Otake and Anne Cutler. Berlin: Mouton de Gruyter, pp. 95-123.

Bell, Allan. 1984. Language Style as Audience Design. Language in Society 13: 145-204. [CrossRef]

Berruto, Gaetano. 2005. Dialect/Standard Convergence, Mixing, and Models of Language Contact: The Case of Italy. In Dialect Change. Convergence and Divergence in European Languages. Edited by Peter Auer, Frans Hinskens and Paul Kerswill. Cambridge: Cambridge University Press, pp. 81-97.

Berruto, Gaetano. 2006. Sociolinguistica dell'italiano Contemporaneo. Roma: Carocci.

Berruto, Gaetano. 2007. Fondamenti di Sociolinguistica. Roma and Bari: Laterza.

Bybee, Joan. 2003. Phonology and Language Use. Cambridge: Cambridge University Press.

Cerruti, Massimo. 2009. Strutture dell'italiano Regionale: Morfosintassi Di Una Varietà Diatopica in Prospettiva Sociolinguistica. Bern: Peter Lang, vol. 7.

Cerruti, Massimo. 2011. Regional Varieties of Italian in the Linguistic Repertoire. International Journal of the Sociology of Language 210: 9-28. [CrossRef]

Cerruti, Massimo, Claudia Crocco, and Stefania Marzo, eds. 2017. Towards a New Standard: Theoretical and Empirical Studies on the Restandardization of Italian. Language and Social Life 6. Berlin and Boston: De Gruyter Mouton.

Cristiano, Angela. 2019. Fenomeni di Riduzione Fonetica nel Napoletano Parlato. Napoli: Università degli studi di Napoli Federico II.

Crocco, Claudia. 2017. Everyone Has an Accent. Standard Italian and Regional Pronunciation. Towards a New Standard: Theoretical and Empirical Studies on the Restandardization of Italian, 89-117. [CrossRef]

De Blasi, Nicola. 2014. Geografia e Storia dell'italiano Regionale. Bologna: Il Mulino.

Farnetani, Edda, and Maria Grazia Busà. 1999. Quantifying the Range of Vowel Reduction in Italian. Paper presented at the 14th International Congress of Phonetic Sciences, San Francisco, CA, USA, August 1-7; vol. 1, pp. 491-94.

Fava, Elisabetta, and Emanuela Magno Caldognetto. 1976. Studio sperimentale delle caratteristiche elettroacustiche delle vocali toniche e atone in bisillabi italiani. In Studi di Fonetica e Fonologia. Edited by Raffaele Simone, Ugo Vignuzzi and Giulianella Ruggiero. Roma: Bulzoni, pp. 35-80.

Grassi, Corrado, Alberto Sobrero, and Tullio Telmon. 1997. Fondamenti Di Dialettologia Italiana. Bari: Laterza.

Hjelde, Arnstein, Bjørn Harald Kvifte, Linda Evenstad Emilsen, and Ragnar Arntzen. 2019. Processability Theory as a Tool in the Study of a Heritage Speaker of Norwegian. In Widening Contexts for Processability Theory: Theories and Issues. Edited by Lenzing Anke, Howard Nicolas and Jana Roos. Amsterdam and Philadelphia: John Benjamins Publishing Company, pp. 185-206.

Johnson, Daniel E. 2009. Getting off the GoldVarb Standard: Introducing Rbrul for Mixed-Effects Variable Rule Analysis. Language and Linguistics Compass 3: 359-83. [CrossRef]

Labov, William. 1984. Field Methods of the Project on Linguistic Change and Variation. In Language in Use: Readings in Sociolinguistics. Edited by John Baugh and Joel Scherzer. Englewood Cliffs: Prentice Hall, pp. 28-53.

Local, John, and Gareth Walker. 2005. Methodological Imperatives for Investigating the Phonetic Organization and Phonological Structures of Spontaneous Speech. Phonetica 62: 120-30. [CrossRef] [PubMed] 
Loporcaro, Michele. 1988. Grammatica storica del Dialetto di Altamura. Pisa: Giardini.

Loporcaro, Michele, Luciano Romito, Antonio Mendicino, and Tizia Turano. 1998. La neutralizzazione delle vocali finali in crotonese: Un esperimento percettivo. In Unità Fonetiche e Fonologiche: Produzione e Percezione, Atti delle 8 Giornate di Studio del Gruppo di Fonetica Sperimentale (A.I.A.), Pisa, 17-19 December 1997 (Collana degli Atti dell'Associazione Italiana di Acustica). Edited by Pier Marco Bertinetto and Lorenzo Cioni. Pisa: Scuola Normale Superiore, pp. 91-100.

Loporcaro, Michele. 2009. Profilo Linguistico dei Dialetti Italiani. Rome and Bari: Laterza.

Marcato, Carla. 2007. Dialetto, Dialetti e Italiano. Bologna: Il Mulino.

Marotta, Giovanna, and Patrizia Sorianello. 1998. Vocali contigue a confine di parola. In Unità fonetiche e fonologiche: Produzione e percezione. Atti delle VIII Giornate di Studio del Gruppo di Fonetica Sperimentale, Scuola Normale Superiore di Pisa, Pisa, 18-20 December 1997. Edited by Pier Marco Bertinetto and Lorenzo Cioni. Pisa: Stamperia SNS, pp. 101-13.

Maturi, Pietro, and Edoardo Mastantuoni. 2012. La variabile schwa nei dialetti campani. In La Variazione nell'italiano e nella sua Storia. Varietà e Varianti Linguistiche e Testuali. Edited by Patricia Bianchi, Nicola De Blasi, Chiara De Caprio and Francesco Montuori II. Firenze: Franco Cesati, pp. 869-78.

Nagy, Naomi. 2009. Heritage Language Variation and Change in Toronto. Available online: https://citeseerx.ist.psu.edu/viewdoc/ download?doi=10.1.1.591.912\&rep=rep1\&type=pdf (accessed on 6 July 2021).

Nagy, Naomi. 2011. A Multilingual corpus to explore variation in language contact situations. Rassegna Italiana di Linguistica Applicata 43: 65-84.

Nagy, Naomi. 2015. A Sociolinguistic View of Null Subjects and VOT in Toronto Heritage Languages. Lingua 164: 309-27. [CrossRef]

Nagy, Naomi. 2018. Linguistic Attitudes and Contact Effects in Toronto's Heritage Languages: A Variationist Sociolinguistic Investigation. International Journal of Bilingualism 22: 429-46. [CrossRef]

Nagy, Naomi, and Alexei Kochetov. 2013. VOT across the Generations: A Cross-Linguistic Study of Contact-Induced Change. In Multilingualism and Language Contact in Urban Areas: Acquisition-Development-Teaching-Communication. Edited by Peter Siemund, Ingrid Gogolin, Monika Schulz and Julia Davydova. Amsterdam: John Benjamins, pp. 19-38.

Nagy, Naomi, and Reynolds Bill. 1997. Optimality Theory and variable word-final deletion in Faetar. Language Variation and Change 9: 37-55. [CrossRef]

Nespor, Marina. 1990. Vowel Deletion in Italian: The Organization of the Phonological Component. The Linguistic Review 7: 375-98. [CrossRef]

Nodari, Rosalba. 2017. Autobiografie linguistiche di adolescenti calabresi. Studi Italiani di Linguistica Teorica e Applicata XLVI: 519-40.

Otheguy, Ricardo, Ana-Celia Zentella, and Daniel Livert. 2007. Language and Dialect Contact in Spanish in New York: Toward the Formation of a Speech Community. Language 83: 770-802. [CrossRef]

Pellegrini, Giovan Battista. 1977. Carta dei dialetti d'Italia. Pisa: Pacini.

Poggi Salani, Teresa. 2010. Italiano regionale. Enciclopedia dell'italiano I: 726-29.

Poplack, Shana, and Marjory Meechan. 1998. How Languages Fit Together in Codemixing. International Journal of Bilingualism 2: 127-38. [CrossRef]

Radtke, Edgar. 1997. I Dialetti della Campania. Roma: Il Calamo.

Reynolds, Bill. 1994. Variation and Phonological Theory. Doctoral dissertation, University of Pennsylvania, Philadelphia, PA, USA.

Rohlfs, Gerard. 1966. Grammatica Storica della Lingua Italiana e dei sui Dialetti. Torino: Einaudi.

Romano, Antonio. 2020. Vowel Reduction and Deletion in Apulian and Lucanian Dialects with Reference to Speech Rhythm. Italian Journal of Linguistics 32: 85-102.

Romano, Antonio, and Francesca Manco. 2003. Incidenza di Fenomeni di Riduzione Vocalica nel Parlato Spontaneo a Bari e a Lecce. In Il Parlato Italiano. Atti del Convegno Naz., Napoli, 13-15 Febbraio 200. Edited by Federico Albano Leoni, Francesco Cutugno, Massimo Pettorino and Renata Savy. CD-rom. Napoli: D'Auria.

Romito, Luciano, Tiziana Turano, Michele Loporcaro, and Antonio Mendicino. 1997. Micro e macrofenomeni di centralizzazione nella variazione diafasica: Rilevanza dei dati fonetico-acustici per il quadro dialettologico calabrese. In Fonetica e Fonologia Degli stili dell'italiano Parlato. Atti delle VII Giornate di Studio del GFS, Napoli 14-15.XI.1996. Edited by Francesco Cutugno. Roma: Esagrafica, pp. 157-75.

Russo, Michela, and William John Barry. 2002. Gradi di elisione dello schwa finale nelle varietà di Ischia e Pozzuoli: Un'analisi strumentale e implicazioni ritmiche. In Atti di XII Giornate di Studio del Gruppo di Fonetica Sperimentale (GFS), Macerata. Edited by Agostino Regnicoli. Roma: Il Calamo, pp. 13-15.

Savy, Renata. 1999a. Riduzioni Foniche nel Parlato Spontaneo: Il Ruolo della Morfologia Nell'interpretazione del Messaggio e nella Comunicazione. Roma: Università da Roma Tre.

Savy, Renata. 1999b. Riduzioni foniche nella morfologia del sintagma nominale nel parlato spontaneo: Indagine quatitativa e aspetti strutturali. In Fonologia e Morfologia dell'italiano e dei Dialetti d'Italia, Atti del XXXI Congresso della SLI. Edited by Paola Benincà, Alberto Mioni and Laura Vanelli. Roma: Bulzoni, pp. 201-21.

Savy, Renata, and Francesco Cutugno. 1997. Ipoarticolazione, Riduzione Vocalica, Centralizzazione: Come Interagiscono Nella Variazione Diafasica? Fonetica e Fonologia Degli Stili dell'Italiano Parlato XI: 177-94.

Silva-Corvalán, Carmen. 1994. Language Contact and Change. New York: Oxford University Press.

Silvestri, Giuseppina. 2018. Word-Final Schwa Licensed by Prosody and Syntax: Evidence from Southern Italian Dialects. Research in Generative Grammar 40. Available online: http:/ / hdl.handle.net/11707/7779 (accessed on 11 July 2021). 
Sornicola, Rosanna. 2002. La variazione dialettale nell'area costiera napoletana. Il progetto di un archivio di testi dialettali parlati. Bollettino Linguistico Campano 1: 131-55.

Telmon, Tullio. 1993. Varietà regionali. In Introduzione all'italiano Contemporaneo. La Variazione e gli usi. Edited by Alberto Sobrero. Rome and Bari: Laterza, pp. 93-149.

Trumper, John, Luciano Romito, and Antonio Mendicino. 2001. Fonetica, fonologia e dialettologia: Un rapporto complesso. In La Dialettologia oggi fra Tradizione e Nuove Metodologie. Edited by Alberto Zamboni, Alberto Del Puente and Maria Teresa Vigolo. Pisa: Edizioni ETS, pp. 93-116.

Van Bergem, Dick R. 1994. Perceptual and acoustic aspects of lexical vowel reduction, a sound change in progress. Speech Communication 16: 329-58. [CrossRef]

Vayra, Mario. 1991. Un'interfaccia Tra Fonetica e Fonologia: Declination Intonativa e Altre ‘Declinazioni' Nel Parlato. In L'interfaccia Tra Fonologia e Fonetica. Atti Del Convegno Di Padova. Edited by Magno Caldognetto and Paola Benincà. Padova: Unipress, vol. XII, pp. 37-154.

Vietti, Alessandro. 2019. Phonological Variation and Change in Italian. In Oxford Research Encyclopedia of Linguistics. Oxford: Oxford University Press. [CrossRef]

Voghera, Miriam. 2001. Teorie linguistiche e dati di parlato. In Dati Empirici e Teorie Linguistiche, Atti del XXXIII Congresso Internazionale di Studi della Società di Linguistica Italiana SLI. Edited by Federico Albano Leoni, Eleonora Stenta Krosbakken, Rosanna Sornicola and Carolina Stromboli. Roma: Bulzoni, pp. 75-95.

Wittenburg, Peter, Hennie Brugman, Albert Russel, Alex Klassmann, and Han Sloetjes. 2006. Elan: A Professional Framework for Multimodality Research. Paper presented at the 5th International Conference on Language Resources and Evaluation, Genoa, Italy, May 22-28. 